\title{
Research on Current Situation and Development of Dragon Boat in Colleges and Universities
}

\author{
Yabin $\mathrm{He}^{1}$, Guoqin Jiang ${ }^{1}$, Yuxiang $\mathrm{Wu}^{1, *}$ \\ ${ }^{1}$ School of Physical Education, Jianghan University, Wuhan 430056, China; \\ *Author for correspondence: 408328331@qq.com
}

Keywords: dragon boat, development, tradition.

\begin{abstract}
With the rapid development of sports at home and abroad, the government also attached great importance to sports. 2016 is the golden year of sports development, the state promulgated a variety of policies, sports development has been listed as a national strategic policy. As a traditional sport in China, the dragon boat sport has a history of more than two thousand years. As the origin and promotion of dragon boat movement, China has been developing rapidly in recent years, and its level has been improved, but the development of China's dragon boat movement relative to foreign countries, there are still many deficiencies in the colleges and universities in China. We investigate the dragon boat project development status and the teaching course, and found the problem and put forward relevant suggestions and measures, hoping to promote the domestic development of dragon boat sports.
\end{abstract}

\section{Introduction}

In 1995 the state explicitly pointed out that we should strive to achieve the coordinated development of national economy, social sports and improve the national health system and level, basically built with national fitness system. The CPC Central Committee and the State Council "on the deepening education reform and promoting quality education" pointed out: "health is the basic premise for young people to serve the motherland and the people, reflected the vitality of the Chinese nation. School education should establish the guiding ideology of health first, strengthen physical education". Dragon boat sport is of great significance to the development of people's own quality.The process of human civilization development to twenty-first century, the trend of global integration is formed, the human society has entered the era of knowledge economy, production, dissemination and application of the development of the economy than ever more dependent on knowledge, knowledge will become the driving force of economic and social development.

The dragon boat sport as a traditional sport in China, has a history of more than 2 thousand. As the origin and promotion of dragon boat movement, China has been developing rapidly in recent years, and its level has been improved. However, in recent years, the dragon boat sport in Southeast Asia and Europe have been valued and developed, China's competitive advantage in the dragon boat race has been a serious challenge. There, these are mainly in China for a long period of dragon boat movement, characteristics, technical and tactical research and attention is not enough; the training of coaches, improve, do not pay enough attention to the dragon boat; youth training, preparing for the personnel training and lack of management method and corresponding measures.

In order to change this situation and better meet the challenges, we must strengthen the training of personnel, increase scientific research, develop a series of appropriate management practices and measures so that the development of China's dragon boat sport has been better. The Chinese dragon boat race, Chinese dragon boat tournament, the Asian Dragon Boat Championships, world championships and the dragon boat races have become a fixed annual sports season, its economic value and social effect and the cultural value become more and more. In the new historical period, , we continue to promote national culture and Chinese civilization international with the dragon culture and folk ritual. The development of dragon boat sports should be guided by the Chinese government. The masses as the foundation, non-governmental organizations are a link, both games and 
entertainment of the dragon boat sport development, establish a scientific management system, the events and social economic and cultural integration, focusing on interactive cooperation with the community units, mobilize non-governmental organizations and enterprises power.

\section{Development of Dragon Boat}

\section{History of Dragon Boat.}

Dragon is a totem of the Chinese nation, for religious rituals, such as worship, along with the development of China's five thousand years of civilization, has now become a symbol of the great Chinese nation. Dragon culture is an important part of Chinese culture, is a symbol of the replacement of the ancient dynasties of China, is a symbol of china. Today, in our daily life often encounter "dragon", such as the fifteen "dragon", "dragon kite" Qingming Festival in March and early May five dragon boat has a "dragon", especially the dragon boat race, which has a long history and widespread. The dragon boat sport is one of the most traditional sports activities, which are popular with people.

The dragon boat sport has a long history in our country, it can be said that it is the product of the combination of social custom and cultural calendar. Dragon Boat Festival is not only a physical representation, more deep social value and significance, it is not only the competitive sports competition, not only to commemorate Qu Yuan, Wu Jiang or more filial daughter, symbolizes the people in the strong survival of the material and spiritual aspects of hope and desire, people pursue mapping in the years of unremitting hard emotional and rational bloom. In Qu Yuan's hometown of Zigui, had a boat to commemorate Qu Yuan's tradition; while in Guangdong and Guangxi, Fujian, Jiangsu and Zhejiang provinces of the ancient Yue people live is the legend of the dragon boat race is the stream to commemorate the national humiliation and humiliation as Goujian snow etc.. However, according to historian and folklorist shows that as early as one thousand years before he jumped in the river boat already exist in the mainland of China south. And the relevant historians believe that the dragon boat race from the original "Dragon Festival" to commemorate the development of Qu Yuan is due to the feudal regime of China to promote cultural needs.

\section{Culture of Dragon Boat.}

The dragon boat sport is a national traditional sports, which integrates the functions of fitness, competition, entertainment and education. It is the embodiment of national culture and spirit. The dragon boat sport has the culture of thousands of years, prosperous from generation to generation, it has deeply rooted in the hearts of the masses, like it not only for the Han people, many ethnic groups is also very popular, and become an important content of the ethnic festivals and cultural exchange activities in the. In addition, the dragon boat race there are many beautiful meaning, touching story, it symbolizes the people of all ethnic groups in the rich emotion, cultivate noble sentiments of the people of all ethnic groups, especially it is beneficial to exercise the people's physique, inspire people to fight the wind and waves hit the rapids, the spirit of unity, cultivate people work together, together with the spirit of collectivism. So it is deeply loved by the people of all ethnic groups.

China is the hometown of dragon boat, two thousand years of dragon boat sport, has been loved by the masses of the people, are widespread, mass characteristics, the formation of a traditional sports cultural and recreational activities, especially it and commemorate the great patriotic poet Qu Yuan combined, more rich seductive charm. The dragon boat sport originated in the production of labor and war in ancient water, primitive ancestors because survival needs fishing on the water especially in the flood of escape, rescue and water fight, competing races, these survival activities become the maternal races.

\section{Development of Dragon Boat in Colleges and Universities}

The standard dragon boat is the domestic and international dragon boat race provided by the form, vessel length and width and height and weight, there are strict requirements, length, length and width of the paddle blade shape, are clearly defined. Make the equipment standard in the competition can be unified. The number of participants 22 people according to the size of the ships ( 20 rowers, drummer, 
helmsman each one), 12 people (10 rowers, drummer, helmsman each one), 5 people (5 rowers), the competition will have open, men's groups, women's groups, mixed groups, adult group, youth group, youth group and the group of veteran game projects have straight game actually speed around the event, and long distance rally etc.

With the establishment of 2004 Chinese University Sports Association branch and branch of the rowing boat, since 2005 the Ministry of Education approved 10 universities for high level sports teams in Colleges and universities boat pilot school, dragon boat movement has entered a new stage, to promote the rapid development of China's dragon boat sport a new force, and constantly improve the level of the dragon boat sport has become one of the most college students love sports.

Although the practice level of College dragon boat has been improved, the theoretical development of the dragon boat sport lags behind the practice level. The establishment of the University team, although also opened on the dragon boat of course, but these courses are elective courses or cultural quality development form, teaching content is also limited in China history, traditional culture, dragon boat, dragon boat, dragon boat world development of the technology, and the content is not systematic, not system.

Table 1. List of all Chinese Dragon Boat Races

\begin{tabular}{ccc}
\hline & Number of College Team & Number of \\
\hline First Session & $\underline{4}$ & $\underline{16}$ \\
Second Session & $\underline{9}$ & $\underline{25}$ \\
Third Session & $\underline{18}$ & $\underline{32}$ \\
Fourth Session & $\underline{23}$ & $\underline{48}$ \\
Fifth Session & $\underline{32}$ & $\underline{69}$ \\
\hline
\end{tabular}

From table 1 of the survey data can be seen, along with the Chinese dragon boat race every year, the number of teams participating by the session increased, while students' team also increased by session, and the total number of teams in the proportion is very large. These data clearly show that Chinese universities attach great importance to the dragon boat sport, the school pays attention to the dragon boat team construction, and the dragon boat culture in high-quality people constantly in the dissemination and development of the Dragon Boat Sport Development Prospects better. The dragon boat sport as an important part of China's dragon boat culture, has been in China for thousands of years of history, has a strong mass base, as a collective sport, its performance in team spirit, patriotic spirit, forge ahead spirit. As a leisure project of physical fitness, psychological adjustment has played a very good role, this is the course on Dragon Boat Sport demands

\section{Conclusions}

The cultural exchange is becoming more and more important in today's society, all kinds of culture only in interact and learn from each other in order to maintain vitality, has made great progress, the dragon boat sport to get better development, so that more and more people to participate in the game, we must increase the Dragon Boat sport and dragon boat culture the publicity, the dragon boat culture is well spread in the world, the western athletic sports competition the characteristics, improve the dragon boat Technology and promote the people of all countries and exchanges between different ethnic groups.

Dragon boat is a traditional Chinese folk sports entertainment, has been circulating for more than two thousand years. The Dragon Boat Sport embodies the Chinese nation, unremitting self-improvement courageously, enterprising spirit, and more and more countries and people's favorite. The dragon boat culture is an important part of China dragon culture, is also the main form of the dragon boat festival sports culture, dragon boat racing has played an important role in the 
cultural heritage, go and eat Zongzi at Dragon Boat Racing has become a distinct cultural symbol of the Chinese nation. The unique symbolic significance, educational value and cultural function of the dragon boat sport can be inherited and developed in the course of the long history evolution, which has become the treasure in the oriental sports.

The development of national traditional sports, is the recognition and promotion of national culture, in the process of national rejuvenation has far-reaching significance. The Dragon Boat Sport with modern sports and fitness in the connotation of patriotism, rendering the festive atmosphere, rich life, improve health, enhance friendship and promote unity plays an active role. The often hold dragon boat races and the formation of a traditional event, can attract more and more teams participate in the competition, and constantly improve the dragon boat sports level and local city level, will further promote the heritage of traditional folk culture, international cultural exchanges become more frequent, the development of dragon boat culture in the world will become more and more widely, the real implementation of the dragon boat races folk culture and common development.

\section{Acknowledgments}

The study was supported by Foundation of Wuhan Sports Bureau (Grant No. 2016Z018). Author for correspondence: 408328331@qq.com.

\section{References}

[1] J.Yuliang,Research on Dragon Boat Races in Xiangyang, Journal of Hubei University of Arts and Science. 33(2013)41-45.

[2] L. Weiguo,F. Jian,W. Xiaoshan, L. Zhiqing, Influence of Traditional Festival and Events Development on Social Culture in Minority Areas-A Case Study of Rong'an Dragon Boat Festival, Journal of Hebei Institute of Physical Education. 25(2011)85-88.

[3] A. Chittick, Competitive Spectacle during China's Northern and Southern Dynasties: With Particular Emphasis on Dragon Boat Racing, Asia Major. 23(2010)65-85.

[4] Z. Liang,L. Wei,L. Daoming, Interactional Research on Fujian Dragon-boat Culture and the Construction of West-strait Economic Zone, Journal of Hebei Institute of Physical Education. 24(2010)84-86.

[5] R.Sarah, M.Richard ,G. Philip ,J. Peter, Physiological and Physical Characteristics of Elite Dragon Boat Paddlers, Journal of Strength \& Conditioning Research.27(2013)137-145.

[6] T. Licheng, The Development Status of Dragon Boat Racing and Countermeasures Analysis, Friend of Science Amateurs. 4(2010)140-142.

[7] L. Bing, Dragon training in China Construction and development of scientific research base, Journal of Northeast Dianli University. 30(2010)89-92.

[8] Z. Yaoyao, Practical Analysis and Discussion on the Tactical of Competitive Dragon Boat Race of 16th Asian Games, A Thesis Submitted for the Degree of Master. Wuhan Institute of Physical Education, 2012.

[9] M. Brooke, Fongzi, dragons and corporate culture: An analysis of corporate dragon-boat paddlers, Journal of Sport and Social Science. 4(2015)99-112. 